care, living arrangements and end-of-life care changes. Advance care directives (ACDs) provide an opportunity for individuals with dementia to communicate their wishes, about these important issues.

Aim The aim of this study was to understand how Australian registered nurses (RNs) use ACDs for individuals with dementia living in residential aged accommodation.

Methods Two hundred and thirty eight RNs working in Australian residential aged care accommodation were recruited via social media, professional organisations and organisations providing residential accommodation. Respondents completed an online survey delivered via Survey Monkey.

Findings $59.7 \%$ of respondents reported commencing discussions around ACDs within the first month of individuals living with a dementia relocating to residential accommodation. However, 42.4\% never or rarely completed ACDs. Only 59.3\% stated that ACDs for individuals with dementia were always or often regularly reviewed. $53.8 \%$ identified that ACDs were always adhered to when an individual's circumstances changed. $62.6 \%$ felt that understanding amongst families about ACDs was sometimes, or often, a barrier to using ACDs.

Conclusion The implementation of ACDs in Australian residential accommodation for those living with dementia remains sub-optimal. The study has demonstrated that ACD documentation and policies describing how they should be used exist; but gaps remain around the practical implementation of ACDs. Strategies to promote communication and collaboration between residential facilities, general practitioners and carers/ families could also assist in providing cohesive, high quality care.

\section{OP90 TRIALS AND TRIBULATIONS OF IMPLEMENTING ACP IN DEMENTIA CARE}

F Bosisio*, E Rubli, R Jox. Lausanne University Hospital, Lausanne, Switzerland

\subsection{6/spcare-2019-ACPICONGRESSABS.90}

Background Although loss of decision-making capacity forms part of the expected trajectory of dementia progression, advance care planning (ACP) is not routine in dementia care.

Methods Dementia-specific ACP intervention piloted with 2030 patient-relative dyads in the context of a university memory clinic in French-speaking Switzerland. Recruiting patients with early dementia and preserved decisional capacity and piloting this intervention unveiled unforeseen obstacles. We want to present these obstacles and discuss potential strategies in order to advance ACP research internationally.

Results Concern that ACP may cause distress to patients and their families was evidenced by the fact that the research ethics committee required formal consent of the patients' primary care physicians as well as an emergency response plan to address distress emerging during ACP. Care professionals in the memory clinic showed substantial gatekeeping, based on a reluctance to inform patients and families about the dementia course and complications and on skepticism about the ethical justification of ACP. The distinction between ACP and traditional advance directives is also unclear to many health professionals who therefore do not see the benefit of ACP. Despite these barriers, people with dementia and their relatives report relief after ACP conversations they had and were satisfied with the tool.
Conclusion Paternalism and misconceptions among healthcare providers have the power to impede research and implementation of ACP. There is an urgent need to increase healthcare providers' awareness and knowledge of ACP in French-speaking Switzerland. Working with patient advocacy groups offers opportunities to promote ACP in dementia care.

\section{OP91 ADVANCE CARE PLANNING BY PROXY FOR ELDERLY PEOPLE WITHOUT DECISION-MAKING CAPACITY}

L Jones*, R Voumard, E Rubli Truchard, R Jox. Lausanne University Hospital, Lausanne, Switzerland

\subsection{6/spcare-2019-ACPICONGRESSABS.91}

Background Advance care planning (ACP) as commonly understood requires decision-making capacity (DMC). When people lose DMC proxies are called upon to make surrogate decisions. ACP by proxy is an extension of classic ACP that specifically promotes patient autonomy in this context. Little research focuses on how ACP by proxy is best conducted, and most ACP research in nursing homes has excluded residents without DMC. Our project aims to identify current proxy planning practices, difficulties and needs, and to explore how ACP by proxy can be implemented in nursing homes in Switzerland.

Methods We present the results of five focus groups; one with physicians of nursing home residents and four with health professionals involved in planning processes in nursing homes in French-speaking Switzerland. Focus groups were audiorecorded and transcribed verbatim. Themes important to the concepts of 'current practice', 'difficulties' and 'future needs' were identified through thematic analysis.

Results Current practices: communication between health professionals, residents, and family, use of advance directives for documentation and as conversation starters, and a variety of systems for recording information. Difficulties: 'timing' of communication with families, interpersonal conflicts, roles of family members, hesitancy talking about end of life care and transfer of information. Future needs: documentation, conversation guides and decision aids specifically adapted for ACP by proxy.

Conclusions The identification of specific needs for ACP by proxy can inform the adaptation of existent tools to facilitate ACP by proxy in nursing homes and therefore promote care in accordance with the presumed wishes of residents without DMC.

\section{OP92 THE CHALLENGES AROUND LOCALISATION OF ACP TRAINING - NEW ZEALAND TRAIN-THE-TRAINER PROGRAMME}

L Manson*, C Arkless, J Goodwin, J Hannah. Health Quality Safety Commission, Wellington, New Zealand

\subsection{6/spcare-2019-ACPICONGRESSABS.92}

Bacground In the very early days of ACP implementation in New Zealand it was identified that one of the greatest barriers was clinicians feeling unprepared to initiate and facilitate ACP conversations. The National ACP Cooperative developed and delivered a programme of training. One component of the programme, the one-day ACP workshop (Understanding more 